\title{
HAEMATEMESIS CAUSED BY AN \\ ULCERATING GALL STONE
}

\author{
By F. Ashton, F.R.C.S. \\ Queen Elizabeth Hospital, Birmingham
}

The chance association of cholelithiasis and gastro-intestinal bleeding must be not uncommon, but for the bleeding to be caused by the gall stone and to be of sufficient degree to necessitate blood transfusion is rare.

\section{Mrs. A.P., aged 62 years}

This patient was admitted to the Queen Elizabeth Hospital on May 19, 1956, with a complaint that for three days previous to her admission she had been passing tarry stools and on the day of her admission she had vomited blood to the extent of half a pint. Prior to her admission for ro years she had been having epigastric discomfort coming on ro to 30 minutes after meals, relieved by vomiting or by taking medicine. She said the pain frequently awoke her at night. She had periods of up to six weeks of pain and then several months of freedom in between.

She had been $\mathrm{X}$-rayed eight years ago and no ulcer had been found. She was said to have a 'dropped stomach.' She had lost rather more than a stone in weight recently.

On examination she was shocked. Her blood pressure was $90 / 55$ and pulse rate 120 , she was sweating and her temperature was raised to $100^{\circ}$. Her liver was enlarged about three fingers' breadths below the right costal margin and there was a tender mass continuous with this going down into the right iliac fossa.

She was transfused and given four pints of blood and on the following day her haemoglobin was 84 per cent.

On June 2 she again had a small haematemesis of about 150 c.c. and again became pale and collapsed and was again transfused, with a substantial improvement in her general condition.

Chest X-ray was normal apart from a small translucency in the lingula, which was thought to be a lung cyst. Cholecystogram showed no contraction or opaque gall stones in the gall bladder and the gall bladder was presumably non-functioning. I.V.P. showed normal renal outlines and no enlargement of the right kidney. Barium mealio showed no evidence of neoplasm or peptic ulcer, 3 . but there was some irregularity in the oesophagus $\omega$ extending up to the aortic arch, which was thought to be due to oesophageal varices.

In view of the previous history of abdominal $\omega$ pain and recent haematemeses, laparotomy was undertaken on June 7 , through a paramedian incision, which revealed a mass in the gall bladder $\vec{c}$ adherent to the duodenum. The liver was not $\stackrel{0}{5}$ enlarged, but was displaced downwards and looked normal. The spleen was not enlarged and the mesenteric vessels were normal in size. The mas $\vec{\varphi}$ formed by the adherent duodenum and ga of bladder was very hard and was thought to be malignant condition. In order to determine the site of the bleeding it was decided to open the duodenum and this was opened at the level of the first part and the incision extended across the $\stackrel{\circ}{\mathbb{D}}$ pylorus into the stomach. In the upper end of the second part of the duodenum on the lateral wall, where tha gall bladder was adherent, there was an ulcerated area which seemed to be due to the mass in the gall bladder eroding through into the duodenum. No other site of bleeding was found in the stomach or duodenum. There was no evidence of gastrostaxis. The nature of the mass in the gall bladder was still undetermined.

On opening the gall bladder there was discharge of about a drachm of thick pus and the hard mass in the gall bladder was found to be due to an enormous gall stone about a hen's egg in size, which was eroding into the duodenum. Owing to the dense adherence of the gall bladder to the of duodenum and surrounding centres, it was thought $N$ unwise to try and remove it, so the stone was evacuated piecemeal. Only a very thin viable membrane remained between the lumen of the duodenum and the lumen of the gall bladder and it seemed beyond reasonable doubt that the site of the haemorrhage in this case was from this eroding gall stone. The incision in the stomach and duodenum was closed transversely and a large tube placed in the gall bladder and the abdomen closed. 
The patient made an uninterrupted recovery from operation.

She was seen subsequently in Out-patients. A barium meal was carried out and this showed the oesophagus, stomach and duodenum were all normal, but a fluid level was found lying lateral to the descending part of the duodenum, which must have been in the gall bladder and through the fistulous communication between the gall bladder and duodenum.

The presence of a fistula was further confirmed by the demonstration of air in the hepatic ducts.

When she was last seen in Out-patients the fistula had closed and she was discharged. She had had no further haemorrhage.

\section{Discussion}

Erosion of the duodenum by gall stones is well known; it is usually a silent process and only comes to light when an operation for gall stone ileus is carried out.

Why in the case reported above erosion was $\stackrel{\curvearrowright}{\complement}$ associated with haemorrhage is not obvious, butc. three reasons may be put forward:

I. The enormous size of the gall stone caused $\stackrel{\vec{F}}{\stackrel{\vec{S}}{+}}$ the necrosis of a large area of duodenal wall.

2. The inability for reasons of size for the stone $\frac{\bar{\sigma}}{\bar{c}}$ to pass into the lumen of the duodenum resulted $\frac{\sigma}{\sigma}$ in long-continued irritation of the duodenal wall. $\propto$

3. The superadded sepsis (pus was found in the gall bladder) may have increased the rate of ulcera- $\overrightarrow{0}$ tion, so that small vessels did thrombose as they normally would with a simple pressure necrosis.

An attempt to find a similar case reported in the literature was unsuccessful.

\section{Acknowledgments}

My thanks are due to Mr. Victor S. Brookes for permission to publish this case.

\section{CARDIAC DISEASE}

Price 4s. 0d. post free

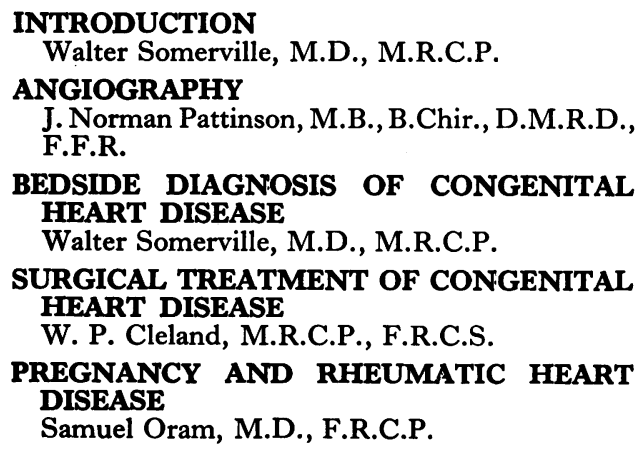

DRUG TREATMENT OF HYPERTENSION

E. G. McQueen, M.B., M.R.C.P., and F. H. Smirk, M.D., F.R.C.P.

\section{TREATMENT OF BACTERIAL} ENDOCARDITIS

Ian G. W. Hill, C.B.E., T.D., M.B., F.R.C.P.E., M.R.C.P., F.R.S.E.

THE MANAGEMENT OF COR PULMONALE J. F. Goodwin, M.D., M.R.C.P.
THE CARDIAC RISK IN ANAESTHESIA AND SURGERY
Graham W. Hayward, M.D., F.R.C.P.

